\title{
The comparison of cost-effectiveness of different drugs used for high blood pressure lowering in the Emergency Department in the University Hospital Centre Tirana, Albania
}

\author{
Ekrem Hasani*, Mimoza Lezha, Elizana Petrela \\ University Hospital Centre "Mother Tereza", Tirana, Albania
}

Objectives: Hypertension is one of the strongest modifiable risk factor for cardiovascular and kidney disease and the leading risk factor for mortality. Rapid controlled reduction of blood pressure (BP) may be necessary to prevent or minimize end-organ damage, despite the increased costs. Aim: To compare the cost-effectiveness of the treatment for the hypertensive crisis.

Patients and Methods: 722 patients (pts) with high BP systolic blood pressure (SBP) $>180$ and diastolic blood pressure (DBP >90 mmHg, without signs of end-organ damage, contraindications for four drugs, who were admitted in the emergency department were enrolled in a prospective, single-blind study. The pts were selected to be treated with 20 mg nifedipine sublingual (s/l) ( $\mathrm{n}=314 \mathrm{pts}), 20 \mathrm{mg}$ furosemid iv ( $\mathrm{n}=102 \mathrm{pts}$ ), nitroglycerin iv $5 \mathrm{mg} / 5 \mathrm{ml}$ starting with $5 \mathrm{mcg} / \mathrm{min}$ initially, increased by $5 \mathrm{mcg} / \mathrm{min}$ every 3 to 5 minutes $(n=63$ pts), $20 \mathrm{mg}$ enalapril $\mathrm{s} / \mathrm{l}(\mathrm{n}=243 \mathrm{pts})$. Electrocardiographic (ECG) recordings and biochemical balance were obtained during and Echocardiographic after the treatment. Checkup of BP was made after $5^{\prime}, 10^{\prime}, 15^{\prime}, 30^{\prime}, 1 \mathrm{~h}, 2 \mathrm{~h}, 4 \mathrm{~h}$, and $6 \mathrm{~h}$ after the treatment, time which was awarded as sufficient for lowering BP $\leq 140 / 90 \mathrm{mmHg}$. Side effects were assessed and the costs were calculated for each patient until normalization of BP.

Results: There were significant differences between the groups regarding the age, SBP and DBP values prior to treatment. The age was respectively $57.79 \pm 10.98$ vs $54.34 \pm 9.35$ vs $51.68 \pm 9.62$ vs $53.66 \pm 11.15 y, p<0.001$. SBP at the start was $185.65 \pm 11.01$ vs $183.02 \pm 0.2$ vs $191.48 \pm 9.33$ vs $180.03 \pm 8.33 \mathrm{mmHg}, p=0.001$ and DBP respectively $98.10 \pm 6.97$ vs $94.85 \pm 6.50$ vs $97.97 \pm 8.05$ vs $92.03 \pm 7.67 \mathrm{mmHg}, p=0.001$. All the antihypertensive drugs significantly reduced SBP and DBP, but more quickly it was done by nitroglycerin and furosemid, this difference was seen in the first $5 \mathrm{~min}$ of the treatment. The values of BP $<140 / 90 \mathrm{mmHg}$ were achieved after $20 \mathrm{~min}$ by nitroglycerine iv $(136.59 \pm 7.16)$, by furosemide iv $(140.53 \pm 7.46$, and after $30 \mathrm{~min}$ by nifedipine s/l $(140.09 \pm 13.64$ and enalapril (137.45 \pm 7.93$), p<0,001$. There was a significant difference $(p=0.017)$ between the groups regarding the cost of the treatment, the highest cost was incurred by nitroglycerin and furosemide, no significant differences were made between nifedipine and enalapril $(p=0.314)$. No side effects were observed during the use of the drugs.

Conclusion: Nitroglycerin iv and furosemide iv act quickly to reduce SBP and DBP, despite the higher costs.

KEYWORDS: antihypertensive drug, furosemid, enalapril.

CITATION: Cardiol Croat. 2013;8(9):320.

\section{Received: $2^{\text {nd }}$ Aug 2013}

*Address for correspondence: Department of Cardiology, University Hospital Center "Mother Tereza" Rr. Dibres 370, city code 1000, Tirana, Albania.

Phone: +355682140304

E-mail: mlezha@ hotmail.com

\section{Literature}

1. Gus M, Andrighetto AG, Balle VR, Pilla MB. Therapeutic approach to patients complaining of high blood pressure in a cardiological emergency room. Arq Bras Cardiol. 1999;72(3):321-6. 